\title{
Structural Variation in Turkish Complex Predicates
}

\author{
Greg Key and Deniz Tat \\ University of Arizona
}

\section{Introduction}

Turkish complex predicates (CPrs) composed of a non-verbal element (NVE) and the verb etmek form a large number of verbs with various argument structures. In the present study, we look at transitive and apparently intransitive CPrs formed with etmek and provide evidence that there are at least two distinct structures underlying each type. Transitive CPrs comprise two structures, one in which the NVE denotes the result state of the theme and as such heads a small clause (Type I), and one in which the NVE is an eventive nominal (Type II). Apparently intransitive CPrs are similarly made up of two distinct structures: one in which the preverbal bare noun has no status as an argument (Type III), and one in which it is the non-case-marked direct object of etmek in its use as a heavy rather than as a light verb (Type IV).

We expand on Folli, Harley \& Karimi’s (2005) analysis of Persian CPrs, extending it to Turkish. The analysis is formulated within the framework of Distributed Morphology (DM). In DM, morphemes-more properly termed "Vocabulary Items" (VI) - realize terminal syntactic nodes. Furthermore, a VI may be underspecified-i.e., it need not be fully specified for all of the features of a node in order to realize it. The primary requirement is that the morpheme not have any features incompatible with the node. Herein, it is argued that etmek (more properly just et-) is a verbalizer with no other featural content. It is the complement of etmek that determines the structure of the CPr. The advantage of this approach is that a single vocabulary item can be employed to realize a wide range of structures.

\section{Transitive CPrs}

Despite superficial similarities, transitive CPrs with etmek fall into (at least) two distinct classes, herein designated Type I and Type II. Type I CPrs are transitive. The internal argument is the theme of a change of state, and the external argument is the cause of the change.

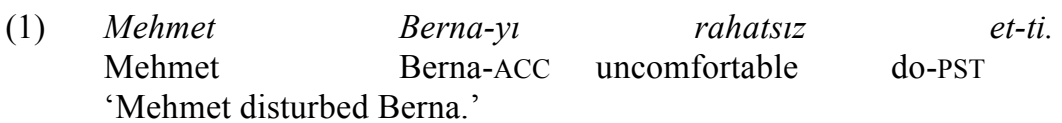

The syntactic category of the non-verbal element ranges over bare nouns, case-marked nouns, and adjectives. The intransitive version of Type I CPrs is formed by changing the LV from etmek to olmak 'become.' 
(2)
Berna rahatsiz
$o l-d u$.
Berna uncomfortable
become-PST

'Berna was disturbed.'

This is the same pattern found in transitive Persian CPrs. The LV kardan 'do' is used in the transitive CPr, and šodan 'become' with the intransitive.

(3)
kard.
Ali Farnaz-ACC uncomfortable
did

'Ali disturbed Farnaz.'

(4)
Farnâz
nârâhat
šod.
Farnaz
uncomfortable
became
'Farnaz was disturbed.'

Folli, Harley \& Karimi (2005) (henceforth FHK) show that the complement of such CPrs in Persian is an Adjective Phrase (AP) or Predicate Phrase (PredP), which forms a small clause (SC) with the internal argument, and cite this as overt evidence of the structure argued for in Hale \& Keyser (1993). The same analysis holds for the Turkish equivalents.

a. Transitive CPr structure

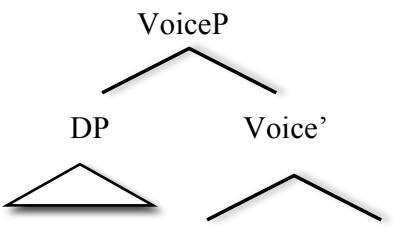

FP<smiles>CCF</smiles>

Voice-ACTIVE

F'

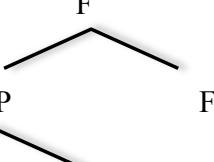

F

b. Intransitive CPr structure

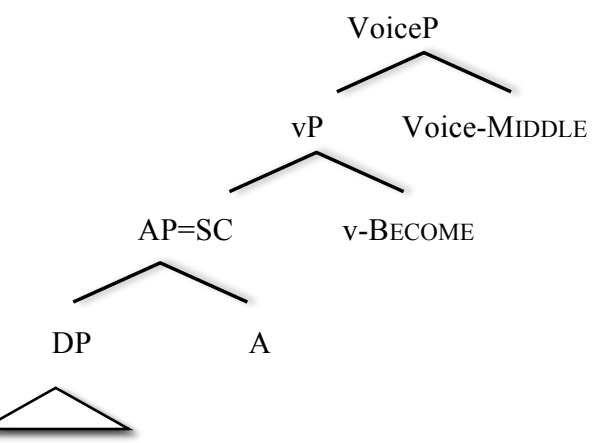

In Turkish, the nodes v-CAUSE and v-BECOME are realized by etmek and olmak, respectively, and in Persian by kardan and šodan. Note that, in FHK, the external argument is introduced in the specifier of vCAUSEP. Herein we follow Pylkkänen (2008) in including a higher Voice projection (distinct from little v). Active Voice, which selects for vCAUSE, 
has an external argument in its specifier. Either way, the LV (little v) is responsible for the presence or absence of an external argument, whether directly (as in FHK), or indirectly via selection (in a Pylkkänen-style approach). Nothing herein hinges on the particulars of the mechanism for introducing the external argument (though see Key 2013 for further motivation for VoiceP).

Type II CPrs are also transitive. However, the internal argument does not undergo a change of state, but is the theme of an action.

$\begin{array}{llll}\text { Mehmet } \quad \text { Berna-yl } & \text { davet } & \text { et-ti. } \\ \text { Mehmet } & \text { Berna-ACC } & \text { inviting } & \text { do-PST } \\ \text { 'Mehmet invited Berna.' } & & \end{array}$

Superficially, these look like transitive Type I CPrs. There are, however, important differences. First, the NV element in Type II does not show the same range of variation as that of Type I. It is always an eventive nominal. Second, Turkish Type II CPrs (unlike Type I) cannot be made intransitive by alternating the LV.

$$
\begin{array}{lll}
* \text { Berna } & \text { davet } & \text { ol-du. } \\
\text { Berna } & \text { inviting } & \text { become-PST }
\end{array}
$$

Intended: 'Berna was invited.'

This is surprising. If the LV etmek is responsible for the presence of an external argument, and hence the transitivity of the verb, as it is in Type I, then replacing it with olmak should result in an intransitive verb. This is highlighted by the fact that in Persian, replacing kardan with šodan achieves this.

$\begin{array}{lll}\text { Farnâz } & \text { da'vat } & \text { šod. } \\ \text { Farnaz } & \text { inviting } & \text { became }\end{array}$

'Farnaz was invited.'

We are left with the fact that Type II CPrs do not allow transitivity alternation via LV alternation, unlike Type I. If the LV determines transitivity in Type I (and in all Persian CPrs), then it would appear not to in Type II. We hypothesize that in Type II, transitivity is determined by the non-verbal element rather than the LV. It can take an accusative argument on its own, even in the absence of an LV.

(9) Kllıçdaroğlu, Auster'i davet için düğmeye bas-tı

Kılıçdaroğlu Auster-ACC inviting for button-DAT press-PST

'Kılıçdaroğlu pressed the button to invite Auster.'

(10) Hasta-yl ziyaret nasil ol-ur?

patient-ACC visiting how be-AOR

'How is visiting patients to be?' 
Thus, the non-verbal element of Type II CPrs is the case-assigning noun (CAN) discuseed in Keskin (2005). They contrast with the NV element of Type I CPrs, which cannot assign accusative case.

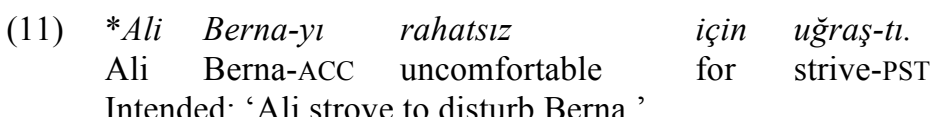

In this way, too, Type II CPrs differ from their apparent Persian equivalents. In Persian, the nominal that appears as an NV element, whether eventive or non-eventive, can never check accusative case in the absence of the LV.

*Farnâz-o da'vat $\quad$ xub mi-sh-e
Farnaz-ACC inviting good DUR-become-3SG
Intended: 'Visiting Farnaz would be good.'

Thus far the generalization holds: If a transitive CPr cannot be made intransitive by alternating the LV, then the non-verbal element can take an accusative argument with no LV (Type II). If LV alternation results in a transitivity alternation, the non-verbal element cannot take an accusative argument in the absence of the agentive LV.

In Type II, the LV is not responsible for the presence of an external argument, or for the transitivity of the CPr. It serves no function other than to turn the nominal into a verb, and is otherwise featurally "empty." It will realize a verbal terminal node if and only if there is no vocabulary item that is more highly specified for that node.

Turkish eventive nominals differ from their Persian counterparts. The key to the structure of Type II CPrs, then, lies in the structure of the nominal itself. It can take an accusative object on its own. This is problematic on standard assumptions about structural case (Chomsky 2001), as Kornfilt (2003) and Keskin (2005) show that accusative case in Turkish is structural, and that it contrasts with inherent cases such as dative. Broadly speaking, there are two possibilities for the nominal. It must either include an accusativeassigning projection within its structure, or be selectable by an accusative-assigning projection. Within DM, the first possibility is ruled out by the fact that these CPrs are passivizable.

$$
\begin{array}{ll}
\text { Berna davet } & \text { ed-il-di. } \\
\text { Berna inviting } & \text { do-PASS-PST } \\
\text { 'Berna was invited.' } &
\end{array}
$$

On the assumption that higher structures cannot suppress lower structures, the passive construction cannot contain an accusative-assigning head within it. We are therefore left with the second option: the highest projection of the nominal is selectable by Voice-ACTIVE and/or an accusative-assigning head. We propose that the Turkish nominals realize the fused terminal nodes $\sqrt{ }$.n.v.

(14) $[\sqrt{ }][\mathrm{n}][\mathrm{v}$ CAUSE $] \rightarrow[\sqrt{ } \mathrm{n}$ v CAUSE $]$ 
This complex head is subjected to a filter, *[n v], which prevents the nominalizing head $\mathrm{n}$ and the verbalizing head $\mathrm{v}$ from occurring on the same node. This in turn triggers impoverishment and deletion of the $[\mathrm{v}]$ feature.

\section{(15) $[\sqrt{ } \mathrm{n}$ v CAUSE $] \rightarrow[\sqrt{ } \mathrm{n}$ CAUSE $]$}

The resulting feature bundle is what is realized by the eventive nominal Vocabulary Item.

\section{(16) a. Turkish:}

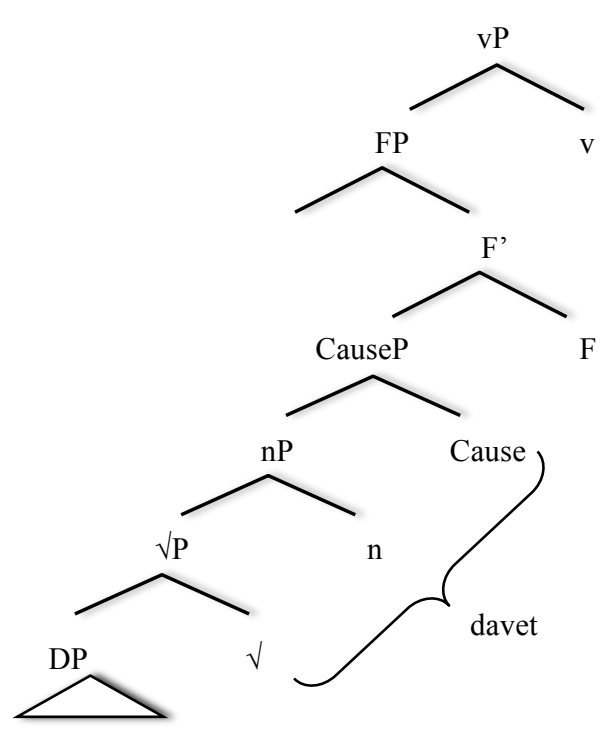

a. Persian:

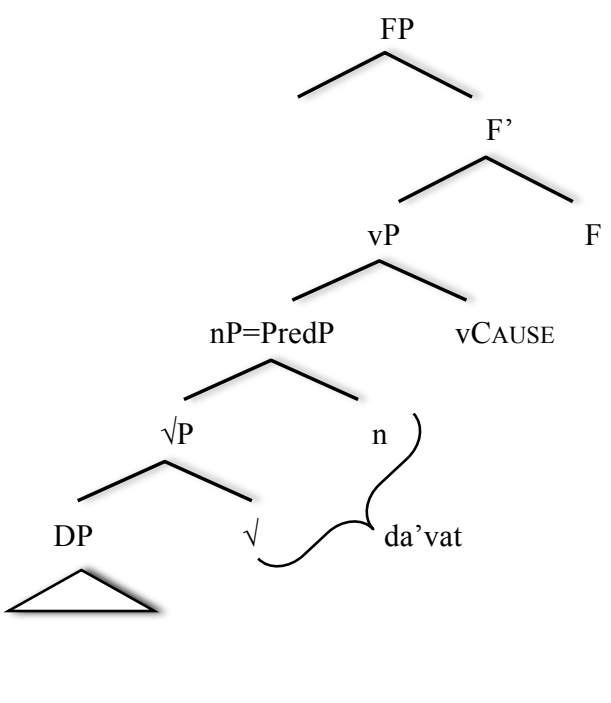

The Turkish nominal can be selected for directly by FP, and thus have an accusative object regardless of whether or not the light verb is present. In these CPrs, the light verb is devoid of 'flavor' (CAUSE, BECOME, DO) and is simply a verbalizer.

There are a number of CPrs that exhibit characteristics of both Types I and II: They have intransitive alternants in olmak, but the nominal can independently take an accusative argument.
a. Mehmet
Berna-yl
ikna
et-ti.
Mehmet
Berna-ACC convincing
do-PST
'Mehmet convinced Berna.'
b. Berna ikna ol-du.
Berna convincing become-PST
'Berna became convinved.'
c. Mehmet Berna-yı ikna için uğraş-tı.
Mehmet Berna-ACC convincing for strive-PST
'Mehmet strove to convince Berna.'


These facts are easily accommodated in a realizational framework such as DM. A vocabulary item such as ikna can realize the head of a small clause Predicate Phrase, or of an eventive Noun Phrase. These items, like etmek, are underspecified, and hence a surface string such as ikna etmek is ambiguous between two realizational structures. In a Type I $\mathrm{CPr}$, a cross-over nominal such as ikna realizes the PredP, while etmek realizes vCAUSE, and in a Type II CPr, a cross-over nominal realizes nP-CAUSE, and etmek realizes $\mathrm{v}$.

It must be acknowledged, however, that the existence of a cross-over class weakens the value of the LV transitive alternation as a diagnostic of structure. Akkuş (2013) brings up further issues with this. In the end, the alternation may not be a sound diagnostic. Nevertheless, there is still reason to suppose that CPrs composed with case-licensing eventive nouns do not share the small clause structure of other transitive CPrs.

\section{Unergative CPrs}

Unergative CPrs with etmek also fall into two distinct structures: a light verb with a nominal NV element (Type III), and a heavy verb with a non-specific (Categorial) direct object. Type III includes a wide range of unergative predicates, exemplified by dans etmek 'to dance' and intihar etmek 'to commit suicide.'

Ahmet dans et-ti.
Ahmet dance do-PST

'Ahmet danced.'

(19) Marilyn Monroe intiharet-ti.

M.M. suicidedo-PST

'Marilyn Monroe committed suicide.'

In a Hale \& Keyser-style approach, an unergative verb is derived from a nominal complement to the LV head-moving into a null LV position. In FHK, Persian unergative CPrs are argued to represent the same structure minus the head movement, and with an overt LV.

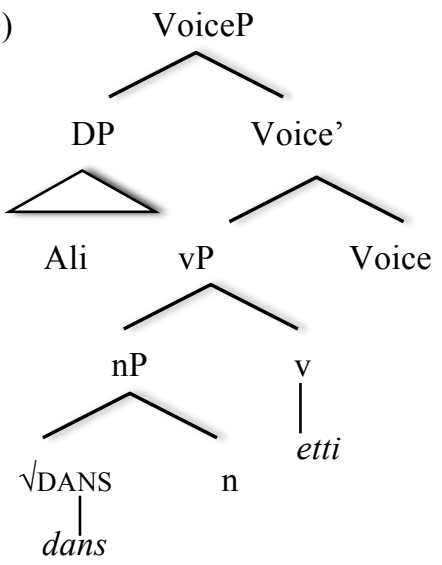


Since the complement is an NV element rather than the object complement of a heavy verb, it should not show properties of a direct object. NV elements cannot be direct objects. (See Aydemir 2004 for several tests that show the difference, such as modification and ellipsis). Hence they cannot take accusative marking. The nominal in Type III CPrs can never be definite, and cannot be accusative-marked.
*Ahmet
bu dans-l
et-ti.
Ahmet
this dance-ACC
do-PST

Intended: 'Ahmet did this dance.'
*Marilyn Monroe
böyle
bir intihar-l
et-ti.
M.M.
this.way
suicide-ACC do-PST

Intended: 'Marylin Monroe committed such a suicide.'

Another test for objecthood comes from the causative construction. The case of the causee in Turkish depends on whether or not the verb has a direct object (regardless of whether it is accusative-marked). If the base verb has no object, the causee is in the accusative case, and if the base verb has an object, the causee is in the dative case.
a. Ahmet
çalış-tl.
Ahmet
work-PST

'Ahmet worked.'

b.

$\begin{array}{lll}\text { Hoca } & \text { Ahmet-i/*Ahmet-e } & \text { çalış-tır-dl. } \\ \text { Teacher } & \text { Ahmet-ACC/ Ahmet-DAT } & \text { work-CAUS-PST } \\ \text { 'The teacher made Ahmet work.' } & \end{array}$

(24) a.
Selin bir kitap oku-du.
Selin a book read-PST
'Selin read a book.'
b. Hoca Selin-e/*Selin-i bir kitap oku-t-tu.
Teacher Selin-DAT/Selin-ACC a book read-CAUS-PST
'The teacher made Selin read a book.'

Under causativization, the causee of Type III CPrs is accusative, indicating that the verb does not have a syntactic object.
(25) Selin Ahmet-i/*Ahmet-e
dans et-tir-di.
Selin Ahmet-ACC/Ahmet-DAT dance do-CAUS-PST
'Selin made Ahmet dance.'
(26) Kennedy Marilyn Monroe-yu/*Monroe-ya intihar et-tir-di.

K. M.M-ACC/M-DAT suicide do-CAUS-PST

'Kennedy made Marilyn Monroe commit suicide.' 
Furthermore, the NV element cannot be modified by a number phrase.
(27) *Ahmet
iki tane dans et-ti.
Ahmet two CLAS dance do-PST
Intended: 'Ahmet did two dances.'

Unergative CPrs of Type IV are superficially similar to Type III, but they differ in several key respects. They are semantically restricted to speech acts, such as dua etmek 'to pray', iltifat etmek 'to compliment', hakaret etmek 'to insult', etc. The nominal can be definite and accusative-marked.

$$
\begin{array}{lll}
\text { Anne-m } m u \quad d u a-y l & e t-t i . \\
\text { Mother-1SG.POSS this prayer-ACC } & \text { do-PST } \\
\text { 'My mother said this prayer.' } &
\end{array}
$$

The causee is in the dative case.
Babam
anne-m-e
dua et-tir-di.
father-1SG.POSS mother-1SG.POSS-DAT
prayer do-CAUS-PST
'My father made my mother say a prayer.'

In addition, the NV element can be modified by a number phrase.
(30)
Anne-m
iki tane dua
mother-1SG.POSS two CLAS prayer
'My mother said two prayers.'
et-ti.
do-PST

These facts point to the following conclusions: The nominal is a direct object. The verb is a heavy verb that means approximately 'to say.'

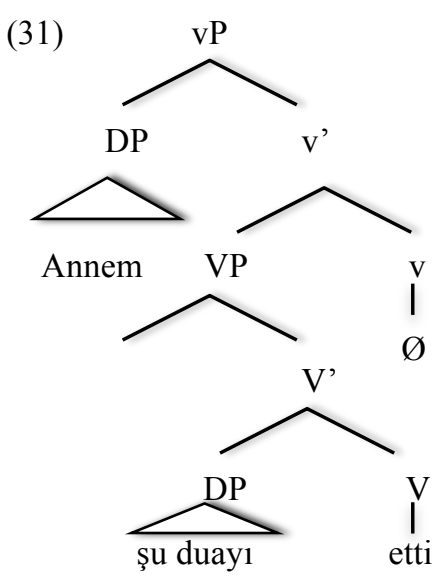


Öztürk (2003) makes a case that preverbal bare nouns composing with etmek are of the category NP, and that they are of the same type as preverbal bare noun 'objects' with heavy verbs, which both she and Aydemir (2004) argue are not syntactic arguments. Our intent here is not to present a fundamental challenge to these analyses, but merely to point out that there is more structural variation in CPrs than has previously been appreciated. At the very least, a distinction must be made between CPrs in which the NVE does not behave like a bare noun occurring before a heavy verb (Type III) and those in which it does (Type IV).

\section{Conclusions}

We have extended the FHK's (2005) analysis of Persian CPrs to Turkish CPrs with etmek and have shown that they have at least four types depending on the complements they take. We have also shown that a realizational approach to Turkish CPrs can account for the variations without positing homophonous Vocabulary Items.

\section{References}

Akkuş, F. 2013. 'Light verb constructions in Turkish: A case for DP predication and blocking.' Paper presented at WAFL 9.

Aydemir, Y. 2004. Are Turkish preverbal bare nouns syntactic arguments? Linguistic Inquiry, Vol. 35/3, 465-474.

Chomsky, N. 2000. Minimalist inquiries. In R. Martin, D. Michaels, and J. Uriegereka, (eds.) Step by step: essays on Minimalist syntax in honor of Howard Lasnik. The MIT Press, Cambridge, MA.

Embick, D. \& Marantz, A. 2008. Architecture and blocking. Linguistic Inquiry, Vol. 39/1, $1-53$.

Folli, R., Harley, H. \& Karimi, S. 2005. Determinants of event type in Persian complex predicates. Lingua 115/10, 1365-1401.

Hale, K., \& S. Keyser, J. 1993. On argument structure and the lexical expression of syntactic relations. In K. Hale and S. J. Keyser, (eds.) The view from building 20: essays in linguistics in honor of Sylvain Bromberger. Cambridge, Mass.: MIT Press, 51-109.

Keskin, C. 2005. Case licensing nouns in Turkish. Utrecht Institute of Linguistics Yearbook.

Kornfilt, J. 2003. Scrambling, subscrambling, and case in Turkish. In S. Karimi (ed). Word order and scrambling. Blackwell Publishing, Malden, MA.

Öztürk, B. 2004. 'Complex predicates in Turkish. Harvard Working Papers in Linguistics

Pylkkänen, L. 2008. Introducing arguments. MIT Press, Cambridge, MA.

\section{Appendix: CPr Types}

Type I

mutlu etmek

razı etmek

tahrik etmek

tatmin etmek

'to make happy'
'to convince'
'to arouse'
'to satisfy'

'to make happy'

'to arouse'

'to satisfy'

$\begin{array}{ll}\text { hall-etmek } & \text { 'to solve' } \\ \text { icat etmek } & \text { 'to invent' } \\ \text { israf etmek } & \text { 'to waste' } \\ \text { kabul etmek } & \text { 'to accept' } \\ \text { kahr-et } & \text { 'to damn' } \\ \text { kayb-etmek } & \text { 'to lose' }\end{array}$




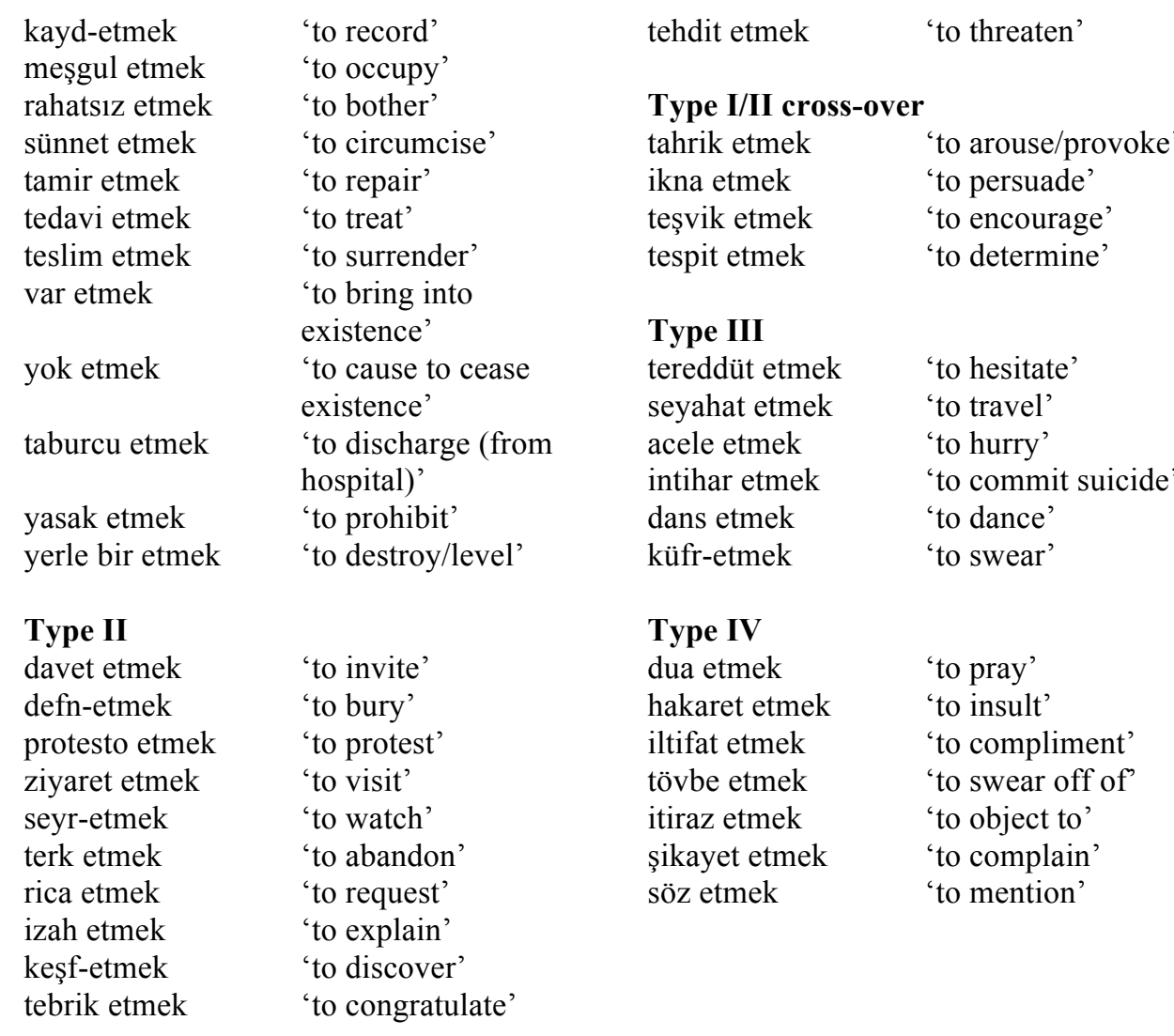

